\title{
ENTREVISTA PSICOLÓGICA: PACIENTES INTERNADOS NO ÂMBITO HOSPITALAR
}

\author{
Giselle Soares da Rocha' \\ Lídia Andressa Silva Leitão Santos ${ }^{1}$ \\ Maria Gabriela de Albuquerque Wanderley ${ }^{1}$
}

\section{RESUMO}

A entrevista psicológica é um instrumento da avaliação psicológica, utilizado por profissionais de psicologia, com técnicas e tempo delimitado. Aplicado ao uso no ambiente hospitalar, é necessária adaptação devido ao ambiente cheio de imprevistos e de adoecimento. Foram utilizados sites de busca e livros sobre psicologia hospitalar e entrevista psicológica para compor o deste estudo. A partir do estudo realizado com o material coletado, foi possível perceber a importância de uma maior discussão sobre os instrumentos utilizados pelos profissionais de psicologia, no enfoque do presente artigo, a entrevista psicológica para uma da eficácia no atendimento à tríade paciente, familiar e equipe de saúde, como também dar voz a subjetividade do paciente, trabalhando as fragilidades, medos, angústias diante da internação.

Palavras-chave: Entrevista psicológica; Psicologia Hospitalar; Hospitalização.

\section{INTRODUÇÃO}

A entrevista psicológica, instrumento da avaliação psicológica, consiste em um "um conjunto de técnicas de investigação, de tempo delimitado" (TAVARES, 2000, p. 45), guiada por um profissional treinado, o qual dispõe-se dos conhecimentos da psicologia, com o objetivo de descrever e avaliar aspectos pessoais com a intenção de realizar intervenções beneficiárias para o entrevistado. Porém, no âmbito hospitalar, as regras que se aplicam à entrevista psicológica devem ser adaptadas para uma condução eficaz em um contexto de imprevisibilidade e de sofrimento, sem retirar a essência da entrevista (ALMEIDA, 2004; DALLAGNOL, GOLDBERG \& BORGES, 2010; TAVARES, 2000).

Stout e Cokk (1999), compreendem que a identificação de problemas comportamentais e psicológicos com a avaliação psicológica torna o atendimento qualificado de acordo com a necessidade de cada paciente. Focando na entrevista psicológica, MacKinnon et al (2008 apud DALLAGNOL, GOLDBERG \& BORGES, 2010) corrobora evidenciando a importância da possibilidade de relacionamento entre os sintomas com a história de vida do paciente, "procurando sempre basear-se na

\footnotetext{
${ }^{1}$ Psicólogas e pós-graduandas em Psicologia Hospitalar pela Faculdade Novo Horizonte.
} 
história de vida em geral, na história clínica e na doença atual" (DALLAGNOL, GOLDBERG \& BORGES, 2010, p. 290).

O papel do psicólogo hospitalar abarca a tríade paciente, família e profissionais de saúde, contribuindo com a qualificação do serviço de saúde, sendo assim, quando falamos em entrevista psicológica ao paciente, abarcamos também seus familiares e a equipe de saúde que o assiste. À família, apoio para lidar com a situação de ter um familiar adoecido, para a equipe, além do apoio, orientações acerca do paciente que Ihes orientem para efetividade do serviço (DALLAGNOL, GOLDBERG \& BORGES, 2010).

Com isto, precisa-se evidenciar a importância de uma entrevista bem feita, pois a efetividade da entrevista também estar relacionada com a eficiência do tratamento psicológico e consequentemente, tratamento médico. Tendo por sua finalização, o entendimento dinâmico desse sujeito (OLIVEIRA, 2005; DALLAGNOL, GOLDBERG \& BORGES, 2010).

Seger (2006) apresenta que um dos motivos para a necessidade da entrevista psicológica é despreparação da equipe de saúde em demandas específicas, ou seja, a psicologia vai atuar justamente nessas dificuldades da hospitalização, no surgimento das demandas que serão tanto familiares, quanto da equipe de saúde, podendo assim, evidenciar a importância dessas intervenções, lembrando que é necessário clarificar o motivo da entrevista tanto para pacientes/família, quanto equipe.

Para realização do presente artigo foi realizado uma revisão bibliográfica numa abordagem qualitativa. De acordo com Minayo e Sanches (1993), a pesquisa qualitativa realiza aproximações fundamentais entre sujeito e objeto uma vez que são da mesma natureza. Segundo Amaral (2007) a revisão bibliográfica é utilizada em pesquisas focais de uma determinada área da ciência a ser pesquisada.

Diante de tais conceitos, foram utilizados sites de busca, sendo eles o "SciELO Brasil" e o "Google Acadêmico", além de livros sobre psicologia hospitalar e entrevista psicológica para compor o conteúdo a ser trabalhado. As palavras chaves utilizadas nos sites de busca foram: "Psicologia Hospitalar"; "Entrevista Psicológica"; "Atuação". Utilizou-se todas as palavras chaves em ambos os sites de busca. Foram encontrados 35 artigos e utilizados três artigos e 1 monografia para o presente trabalho. Seguindo o seguinte critério de inclusão e exclusão: arquivamento de artigos que contavam em 
seu resumo assuntos referentes aos objetivos; e excluídos os que ao longo da leitura divergiam com os pontos investigados.

\section{Psicologia Hospitalar}

O processo de internação, vivência da doença, procedimentos cirúrgicos trazem mudanças na vida do paciente e de sua família, bem como na dinâmica familiar. Segundo Campos (1995) o psicológico do paciente e da família é comprometido diante de uma doença instalada. Sendo assim, o papel do psicólogo no contexto hospitalar se faz necessário prestando assistência psicológica, escuta qualificada, apoio e orientação.

\footnotetext{
O diálogo com o psicólogo ajudará o paciente a sentir-se compreendido, aceito e assistido como um todo, tomando consciência dos seus problemas, de seus medos, fantasias, perdas, refletindo o significado do seu adoecer (Campos, 1995, p. 91).
}

Em sua atuação, o psicólogo hospitalar atenderá o paciente internado, seja através de busca ativa ou através do encaminhamento da equipe de saúde, ajudando o paciente no processo de reestabelecimento físico, psicológico e social. Desta forma, o profissional de psicologia em sua prática utilizará de instrumentos que dará a condições de uma assistência qualificada ajudando o paciente em seu processo de adoecer, como também de internação. Neste contexto, a entrevista psicológica, de acordo com Tavares (2000), tem um foco nos sintomas e nas vivências significativas da vida do sujeito, visando-o como um todo.

\section{A entrevista psicológica e a hospitalização}

No âmbito hospitalar o primeiro contato do profissional de psicologia com o paciente se dar através da entrevista focal, considerando o seu momento atual e o contexto histórico. É de suma importância que durante a entrevista o psicólogo se utilize de uma linguagem clara para que o paciente compreenda de forma consciente o que é pontuado.

\footnotetext{
O que se usa mais frequentemente no hospital é a entrevista focal, quando tentamos compreender o paciente levando em conta o momento pelo qual está passando, ou seja, a sua doença e a sua hospitalização. [...] Deve-se ser um agente facilitador da angústia do paciente e, dentro do possível pontuar situações para ajuda-lo (BATISTA, 2019, p. 18).
}

A entrevista é uma técnica que pode ser aplicada tanto para prevenção ou diagnóstico, pois possibilita através de dados colhidos, compreender o paciente tanto 
em sua história de vida como sua vivência atual. Além da obtenção de dados, a entrevista ajudará a estabelecer o rappot entre o paciente e o psicólogo.

Em suas diversas formas e estruturas, a partir de vários enfoques teóricos, podemos citar três tipos de entrevistas. De acordo com Oliveira (2005), entrevistas diretivas ou fechadas, onde as perguntas são sequenciais e sem alterações na ordem; A entrevista livre, não-diretiva ou aberta, a qual é ajustável, permitindo assim um exame mais desmedido do entrevistador para a personalidade do paciente entrevistado; E a entrevistas semidirigida, que oferece mais liberdade ao paciente, porém é objetiva com propósito de uma procura clara para as informações obtidas.

A aplicabilidade de uma entrevista no contexto hospitalar vai exigir do profissional algumas adaptações, necessitando de flexibilidade e criatividade do profissional. De acordo com Dallagnol et al (2010) o setting terapêutico é adaptável ao tempo, delimitado ao local da entrevista e tem caráter sigiloso. Contudo, diante do contexto hospitalar, o comprometimento do sigilo pode ser encarado por certa movimentação existente, por exemplo, pela questão de leitos próximos.

É preciso então, a adaptação do momento, que se junta com a criatividade e habilidade para uma abordagem bem desenvolvida. É importante ressaltar que a família ocupa lugar importante nesse processo. Dependendo da idade do paciente, no caso de crianças, as informações dadas pela família sobre o paciente pode ajudar a compreender melhor o que está acontecendo, como também serem orientadores em questão de cuidados com a criança. Em contraponto, a família, também deve estar sendo assistida, recebendo assistência psicológica, atendendo a tríade pacientefamília-profissionais da saúde (DALLAGNOL, GOLDBERG \& BORGES, 2010).

Ao analisarmos o tema proposto neste artigo, sentimos emergir de tais discussões, o entendimento do conceito de entrevista psicológica em pacientes internados no âmbito hospitalar. Diante desse fator observa-se que a entrevista psicológica tem uma direção, um objetivo no que se refere a descrição, avaliação e intervenção de forma adaptada e conduzida. Propomos então, por papel da psicologia, a compreensão e identificação das necessidades de cada paciente, levando em consideração não só os seus comportamentos apresentados permeados por sintomas, como também o reforço a necessidade de compreender que seu histórico e contexto vivenciado pelo paciente são necessários em tal avaliação (DALLAGNOL, GOLDBERG \& BORGES, 2010; OLIVEIRA, 2005; SIMONETTI, 2011). 
A psicologia nesse âmbito contribui para uma efetivação com mais qualidade no atendimento do serviço em saúde. A inserção do psicólogo no hospital gera qualidade, amplia a promoção de saúde e a qualidade no atendimento. $O$ atendimento psicológico por sua vez tem característica focal, no que avalia a situação do paciente e analisa a forma que o paciente enfrenta a situação demandada e a manifestação desse paciente no aqui e agora, o psicólogo tem que observar e ouvir de maneira atenta e paciente as palavras, como também seus silêncios. Contudo, uma entrevista bem realizada pode traduzir as questões subjetivas do paciente e assim trazer consequências positivas ante a equipe multidisciplinar, com a finalidade de um vínculo de confiança favorável e eficaz (DALLAGNOL, GOLDBERG \& BORGES, 2010; OLIVEIRA, 2005; SIMONETTI, 2011).

\section{CONSIDERAÇÕES FINAIS}

Diante do conteúdo exposto, é possível identificar a necessidade de atuação do psicólogo hospitalar e a utilização da avaliação psicológica, sendo contempladas as intervenções num contexto de imprevisibilidade, cuja preocupação central é que a entrevista não perca sua essência em meio ao sofrimento e expectativas. Diante disso, o psicólogo consegue dar voz a subjetividade do paciente, podendo trabalhar suas fragilidades, medos, angústias diante da internação.

Percebe-se então, a importância de uma maior discussão sobre os instrumentos utilizados pelos profissionais de psicologia, dando ênfase a entrevista psicológica, visto a relevância da mesma no contato com o paciente. Sendo possível o estabelecimento da eficácia do atendimento à tríade paciente, familiar e equipe de saúde. Identificou-se também, durante a revisão bibliográfica, a carência de artigos referentes a entrevista psicológica no âmbito hospitalar, afirmando a necessidade de mais estudos que abordem essa temática. 


\section{REFERÊNCIAS}

ALMEIDA, N. V. A entrevista psicológica como um processo dinâmico e criativo.

PSIC - Revista de Psicologia da Vetor Editora, v. 5, n.1, p. 34-39, 2004.

Disponível em: <http://pepsic.bvsalud.org/scielo.php?script=sci_arttext\&pid=S167673142004000100005>. Acesso em: 29 fev. 2020.

AMARAL, J. J. F. Como Fazer Uma Pesquisa Bibliográfica. 2007. Disponível em: <http://200.17.137.109:8081/xiscanoe/courses-

1/mentoring/tutoring/Como\%20fazer\%20pesquisa\%20bibliografica.pdf>. Acesso em: 08 mar. 2020

BATISTA, M. Ensaios de psicologia hospitalar: $O$ atendimento com humanização e sensibilização. Maringá: Viseu. 2019.

CAMPOS, T. C. P. Psicologia Hospitalar, a atuação do psicólogo em hospitais. São Paulo: Editora EPU. 1995.

DALLAGNOL, C.; GOLDBERG, K.; BORGES, V. R. Entrevista Psicológica: Uma Perspectiva do Contexto Hospitalar. Revista de Psicologia da IMED, v. 2, n. 1, p. p. 288-296, 2010. Disponível em:

$<$ https://seer.imed.edu.br/index.php/revistapsico/article/view/40>. Acesso em: 28 fev. 2020.

MINAYO, M. C. S.; SANCHES, O. Quantitativo-qualitativo: oposição ou complementariedade. Caderno de Saúde Pública. Rio de Janeiro, v. 9, n. 3, p. 239262. jul/set, 1993. Disponível em: <http://www.scielo.br/scielo.php?pid=S0102311X1993000300002\&script=sci_abstract\&tlng=pt>.

Acesso em: 08 mar. 2020.

OLIVEIRA, M. de F. Entrevista Psicológica - O caminho para aceder ao outro. 2005. 37p. Monografia (Psicologia da Saúde). Universidade Lusíada do Porto, Psicologia.com.pt, 2005. Disponível em:

$<$ https://www.psicologia.pt/artigos/ver_artigo_licenciatura.php?codigo=TL0031>. Acesso em: 29 fev. 2020

SEGER, A. C. Entrevista clínica no contexto hospitalar: revisões e reflexões. In: MACEDO, M. M. K., CARRASCO, L. K. (Com) textos de entrevista - Olhares diversos sobre a interação humana. São Paulo: Casa do Psicólogo. 2006. p. 247259

SIMONETTI, A. Manual de Psicologia Hospitalar: o mapa da doença. 6. ed. São Paulo: Casa do Psicólogo. 2011.

STOUT, C. E.; COOK, L. P. New Areas for Psychological Assessment in General Health Care Settings: what to do today to prepare for tomorrow. Journal of Clinical Psychology, v. 55, n. 7, p. 797-812,1999. Disponível em:

<https://onlinelibrary.wiley.com/doi/pdf/10.1002/\%28SICl\%2910974679\%28199907\%2955\%3A7\%3C797\%3A\%3AAID-JCLP3\%3E3.0.CO\%3B2-O>. Acesso em: 28 fev. 2020. 
TAVARES, M. Entrevista Clínica. In: CUNHA, J. A. et al. Psicodiagnóstico - V. Porto Alegre: Artmed. 2000. p. 45-56. 